\title{
PROPERTIES OF CHITIN REINFORCES COMPOSITES: A REVIEW
}

\author{
M. I. Ofem ${ }^{1,}{ }^{*}$, A. J. Anyandi ${ }^{2}$ and E. B. Ene ${ }^{3}$ \\ 1,2,3 Mech. Engineering DePartment, Cross River Univ. of TeChnology Calabar, Crossriver State. Nigeria \\ E-mail addresses: ${ }^{1}$ ofemic@yahoo.com, ${ }^{2}$ anyandi@yahoo.com, ${ }^{3}$ enechinelo@yahoo.com
}

\begin{abstract}
This paper provides a review of chitin, sources, extraction, uses, applications, chitin whiskers and it preparations and the mechanical and thermal properties of chitin reinforced composites. Also reported here is the properties of $\mathrm{CaCO}_{3} / \mathrm{chitin}$ whiskers reinforced composites. Chitin can be extracted from shrimps, crabs cell walls, yeast and green algae or from Riftia tubes with a percentage varying between 20 to 40\% depending on the source. Despite the denaturing of chitin, the most widely used method of extractiong chitin from seashells is the chemical method. Chitin whiskers known by different name in literature can only be prepared by using hydrochloric acid. The rod-like particles of chitin whiskers have an average lengths and widths of $200 \pm 20 \mathrm{~nm}$ and $8 \pm 1 \mathrm{~nm}$ respectively or more depending on the source of chitin. Chitin whiskers reinforced composites have greatly improved the mechanical and thermal properties of the composites especially at lower filler loading. The improved properties are attributed to effective stress transfer.
\end{abstract}

Key words: Chitin, mechanical, thermal, properties, biomaterials

\section{INTRODUCTION}

Research on nanocomposites has been on the increase, which can be attributed to their improved properties compared to neat polymers [1-2]. A class of new composites which has equally attracted research are the bio-based composite materials. This interest is based on the fundamental advantages; being renewable materials they contribute little or nothing to the depletion of energy resources and they are environmentally friendly. Another major reason for the interest is the gradual increase in the price of oil-based products and the destructive effects on the environments of these products [3]. Research into the properties of bio-based reinforced polymers has been reported [4-6]. These materials have shown good mechanical and thermal properties. One major bio material that research is ongoing is chitin.

Chitin is a naturally occurring renewable and biodegradable polysaccharide, it is a mechanically stable, nontoxic and physiologically inert polymer [7]. Chitin is a co-polymer of $\mathrm{N}$-acetyl-glucosamine and $\mathrm{N}$-glucosamine units, either randomly or blockly distributed throughout the biopolymer chain. When the number of $\mathrm{N}$-acetylglucosamine units is higher than $50 \%$, the biopolymer is termed chitin, when the number of $N$-glucosamine units is higher, the term chitosan is used [8].

Being the second most abundant natural polymer after cellulose [9], it consists of 2-acetamido-2-deoxy-D- glucose via a $\beta(1-4)$ linkage. Chitin can be extracted from its sources by biological, fermentation and chemical methods [10-12]. The chemical method which is the most widely used involves acid and alkaline treatments and de-pigmentation stage to remove astaxantine [12]. The physicochemical characteristics (crystallinity, molecular weight, moisture and ash content, protein and deacetylation degree (DD)) of chitin and its derivative chitosan can be determined using various methods [12] Chitin whiskers (CHW), which can be produced by acid hydrolysis, are rod-like nanofibrils with dimensions of 5$70 \mathrm{~nm}$ in width and $150-800 \mathrm{~nm}$ in length [13] depending on the source. Because of their high longitudinal and transverse moduli of $150 \mathrm{GPa}$ and 15 $\mathrm{GPa}$, respectively, [11, 14], CHW can be used as nanofillers for reinforcement in polymers. Different techniques of producing polymer/CHW composites have been established these are casting and evaporating [15], non-aqueous solvent dispersion [16] polymer grafting [17] and freeze-drying and hot pressing [11]. Using CHW as reinforcement has greatly improved the mechanical properties especially at lower filler loading [11, 16-17]. Here we take a comprehensive review of sources of chitin and its extraction, preparation of chitin whiskers, mechanical and thermal properties of chitin reinforced composites, other properties and the biomimetic synthesis of $\mathrm{CaCO}_{3}$ properties of chitin reinforced polymer composites. 


\section{CHITIN SOURCES}

A shell is the hard, protective outer layer of a marine or aquatic animal, such as a mollusc. Animals with shells can be found in rivers, streams, sea or the oceans. This protective outer layer of a marine animal is referred to as exoskeleton. Examples of animals with exoskeletons are shrimps and crabs. To reduce weight and at the same time maintain high environmentally friendly physical, chemical and mechanical properties of materials, attention is focused on the properties of these exoskeleton sometimes refer to as seashells. One of the striking features of the seashells is the presence of a biodegradable polymer called chitin. Chitin, being a homopolymer of $\beta-(1 \rightarrow \quad 4)$-linked N-acetyl-Dglucosamine is one of the most abundant renewable, natural polymers second only to cellulose [18].

Chitin can be extracted from different sources; shrimps and crabs [19-20], cell walls and structural membranes of fungi, yeast and green algae [21-22] and from Riftia tubes [11]. Most sources of chitin contain 30 to $60 \%$ minerals, 0 to $14 \%$ lipids, 20 to $40 \%$ protein and 20 to $30 \%$ chitin [23], with calcium carbonate, protein and chitin constituting about $90 \%$ [21]. However a recent review [24] shows that chitin varies with species. Details sources of chitin, type, \% content and conditions for extraction is presented in Table 1.

It has been estimated that between $10^{12}$ to $10^{14}$ tons of chitin is produced every year in the biosphere most of it in the ocean [25-26]. As per a published report of chitin production by arthropods, the total annual production in aquatic environments is estimated to be $28 \times 10^{6}, 1328 \mathrm{x}$ $10^{6}$ and $6 \times 10^{6}$ tons of chitin for freshwater, marine ecosystems and athalassohaline ecosystems respectively [27].

\subsubsection{Extraction of Chitin}

There are various techniques used in the extraction of chitin. Chitin can be extracted by fermentation and biological methods. While the extraction of chitin by fermentation is very expensive [28], biological extraction does not denature the chitin, is cost effective and ecofriendly [10] and recovery of protein hydrolysate with amino acid composition can be achieved [29]. Another method that has been widely reported is the chemical method [11-12, 30-31].The chemical method for the isolation of chitin from seashells involve demineralization of inorganic matter (calcium carbonate) using dilute acid, deproteinization (protein) using alkaline solution and bleaching/decolouration using sodium chlorite and to an extent deacetylation using over $40 \%$ concentration of $\mathrm{NaOH}$ or $\mathrm{KOH}$ to get chitosan, a derivative of chitin. The use of chemicals (high temperature, strong acid and alkaline treatment) to isolate chitin from seashells not only result in harmful waste (acid and alkaline) to the environment and increase in cost of chitin purification, but also gives depolymerisation of the chitin there by affecting the molecular weight and viscosity after solubilisation $[23,32]$. These disadvantages of chemical methods of extraction led to the development of biological methods.

As stated earlier, chemical methods of chitin extraction involves demineralization using strong acid. Some of the acids that can be used include; $\mathrm{H}_{2} \mathrm{SO}_{4}, \mathrm{HCOOH}, \mathrm{CH}_{3} \mathrm{COOH}$, $\mathrm{HNO}_{3}$ and $\mathrm{HCl}$. Of these the most widely used is $\mathrm{HCl}[12$, 33]. Use of $\mathrm{HCl}$ allows almost the complete removal of organic salts. While deproteinization is done mostly with $\mathrm{KOH}$ or $\mathrm{NaOH}$, it can equally be done with proteolytic enzymes [10, 29]. Pigments are removed using sodium chlorite, hydrogen peroxide or $0.02 \%$ of potassium permanganate at $60^{\circ} \mathrm{C}$. A detailed explanation of chitin extraction by chemical method is reported by Aranaz et al., [12].

The need for a cost effective process and non-denaturing of the chitin during the extraction process, led to the development of the biological methods. A review [24] of biological methods has shown that it can replace the conventional method of chitin extraction. Synowiecki and Al-Khateeb [29] while isolating chitin from shrimp crangonusing enzymes, recovered protein hydrolysate having good values of protein efficiency ratio and essential amino acid. The demineralization of crab shells were carried out using lactic acid bacteria as against hydrochloric acid, while deproteinisation was done by fungus aspergillus niger [10]. The result shows a comparable yield \% (chemical to biological method) of 28.1 to $22.6,27.35$ to 20.8 and 27.05 to 20.15 for shell to acid ratios of 1:15, 1:25 and 1:35 respectively. Most importantly the chitin obtained was partially soluble compared to the chemical method.

Using Bacillus licheniformisas an enzyme, the isolation of chitin from shrimp shells yielded a better viscosity quality than commercial chitin. The viscosity (soluble fraction in diluted $N$-methyl-2-pyrrolidone-LiCl at a concentration of $0.1 \mathrm{wt} \%$ ) obtained was $80 \mathrm{mPa}$.s compared to $10 \mathrm{mPa}$.s for commercial chitin [23]. Similarly, Khanafari et al., [34] comparative study of chitin and chitosan extraction from shrimp waste using chemical and biological methods, showed that the biological method were better as it consumed less energy and time, and reduced the quantity of solvent used. A one-step co-fermentation process of isolating chitin from red crab shell was developed by Jung et al., [35]. This method simultaneously removed ash and protein. A schematic biological extraction method is presented in Figure 1. 
Table 1: Conditions of extraction of chitin from sea sources and extracted chitin characteristics [18 (modified)]

\begin{tabular}{|c|c|c|c|c|c|c|}
\hline chitin source & $\begin{array}{l}\text { bath } 0.55 \mathrm{M} \mathrm{HCl} \\
\text { Time(h) }\end{array}$ & $\begin{array}{r}\text { Alkaline bath } 0.3 \mathrm{M} \\
\text { Time(h) }\end{array}$ & $\mathrm{NaOH}$ & $\begin{array}{l}\mathrm{H}_{2} \mathrm{O}_{2} \\
\text { treatment }\end{array}$ & $\begin{array}{c}\text { Chitin content } \\
\text { (\%) }\end{array}$ & $\begin{array}{l}\text { Type of } \\
\text { chitin }\end{array}$ \\
\hline Barnacle (Lepasanatifera) & 2 & 4 & & Yes & 7 & $\alpha$ \\
\hline Red crab (Portunuspuber) & 5 & 3 & & Yes & 10 & $\alpha$ \\
\hline $\begin{array}{l}\text { Spider crab (Maia } \\
\text { squinado) }\end{array}$ & 3 & 3 & & Yes & 16 & $\alpha$ \\
\hline $\begin{array}{l}\text { Lobster (Homarus } \\
\text { vulgaris) }\end{array}$ & 3 & 3 & & Yes & 17 & $\alpha$ \\
\hline $\begin{array}{l}\text { Locust lobster } \\
\text { (Scyllarusarctus) }\end{array}$ & 2 & 3 & & Yes & 25 & $\alpha$ \\
\hline $\begin{array}{l}\text { Spiny lobster (Palinurus } \\
\text { vulgaris) }\end{array}$ & 3 & 7 & & Yes & 32 & $\alpha$ \\
\hline $\begin{array}{l}\text { Crayfish } \\
\text { (Astacusfluviatilis) }\end{array}$ & 2 & 3 & & Yes & 36 & $\alpha$ \\
\hline $\begin{array}{l}\text { Shrimp } \\
\text { (Palaemonfabricius) }\end{array}$ & 3 & 3 & & Yes & 22 & $\alpha$ \\
\hline Squilla (Squilla mantis) & 3 & 3 & & Yes & 24 & $\alpha$ \\
\hline $\begin{array}{l}\text { Cuttlefish (Sepia } \\
\text { officinalis) }\end{array}$ & 3 & 3 & & No & 20 & $\beta$ \\
\hline Squid (Loligo vulgaris) & 3 & 2 & & No & 40 & $\beta$ \\
\hline Marbled crab(Grapsusmarmoratus) & 3 & 3 & & Yes & 10 & $\alpha$ \\
\hline
\end{tabular}

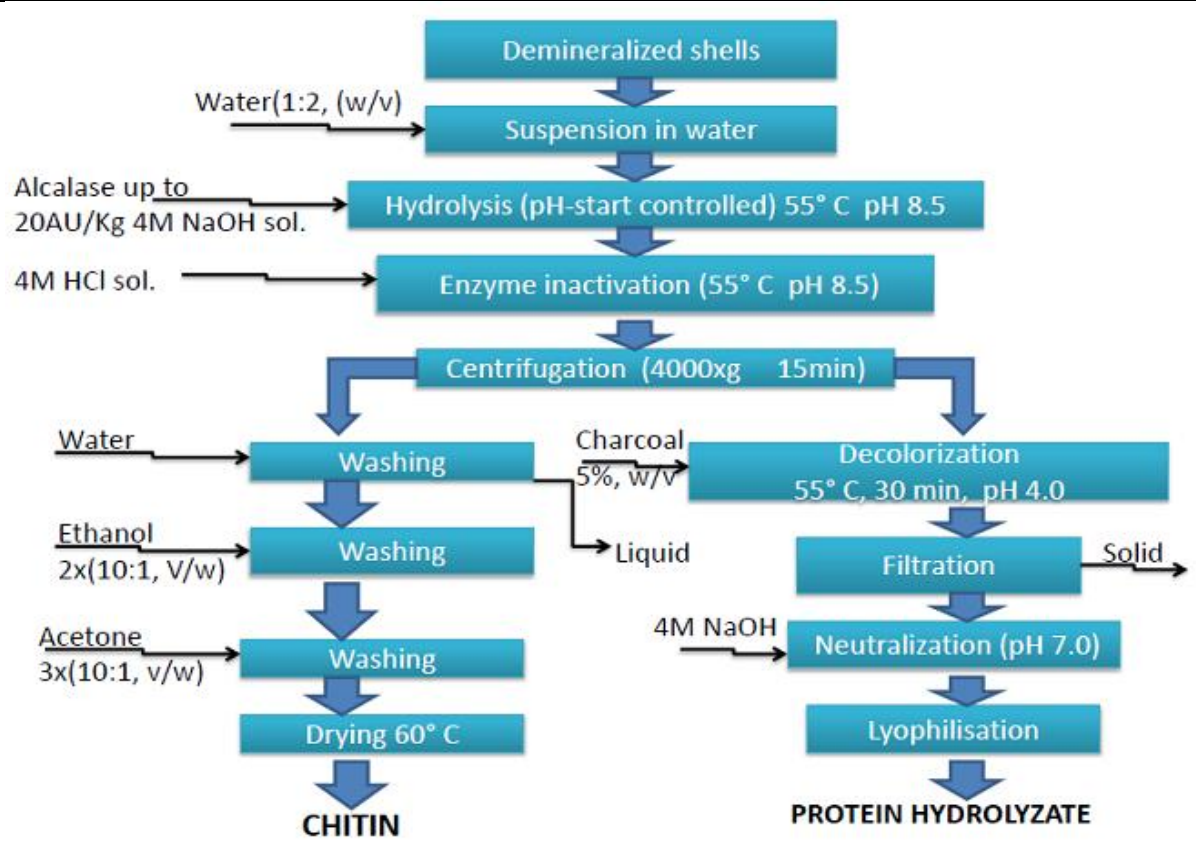

Figure 1: Flow-sheet for production of chitin and protein hydrolysate from shrimp C. Crangon shell waste. [29].

\subsubsection{Deacetylation of Chitin}

Depending on the source, three polymorphic forms of chitin are found in nature; namely $\alpha, \beta$ and $\gamma$ chitins [12, 36].The most common and extensively investigated is $\alpha$ chitin because is stable and widely found in living organisms (see Table 1). Chemical chitin is identical to cellulose but that the secondary hydroxyl on the alpha carbon atom(C-2) of the cellulose molecule is substituted with an acetamide group, also the removal of acetyl group in the alpha carbon atom results in the formation of chitosan (Figure2). The deacetylation of chitin with $\mathrm{NaOH}$ or other alkaline result in the production of chitosan. Aranaz et al., [12] stated two methods of chitosan preparation, depending on the level of deacetylation. These methods are the heterogeneous deacetylation of solid chitin and homogeneous deacetylation of pre-swollen chitin under vacuum in an aqueous medium. In both cases up to 80 hours is needed to produce chitosan. In order to reduce the long processing time, and a reduction in the quantity of alkali used, Domard and Rinaldudo [37] developed a successive alkali treatment method using thiophenol in dimethylsulfoxide (DMSO). Mima et al., [38] developed an intermittent water washing method while Pelletier et al., [39] developed a thermo-mechanical process using a cascade reactor operating under a low alkali concentration. 


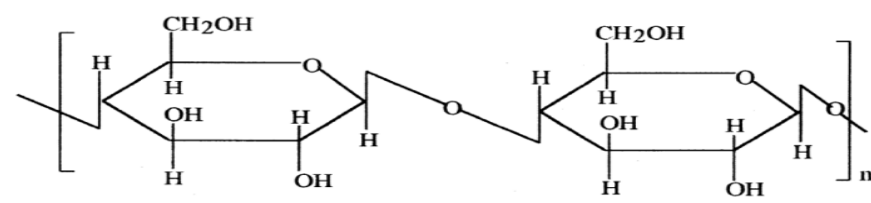

Cellulose

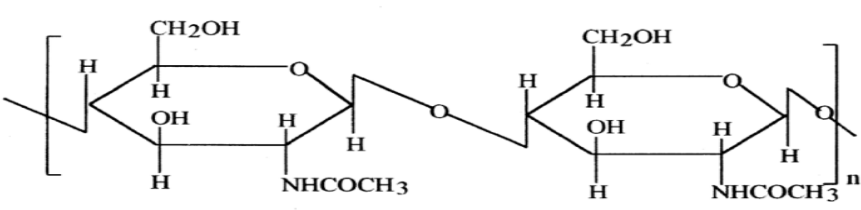

Chitin

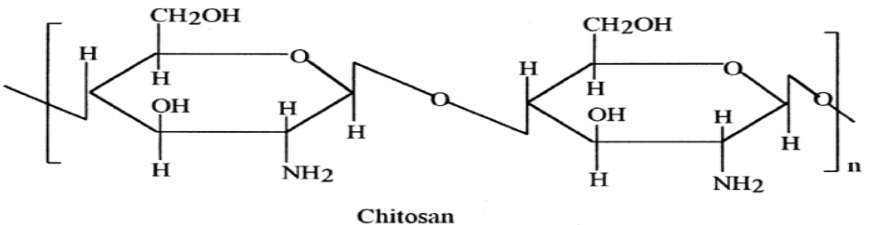

Figure 2: Chemical structures of cellulose, chitin and chitosan [40].

\subsection{Chitin Whiskers}

As was stated earlier chitin is known to form microfibrillar arrangements in living organisms, embedded in a non-fibrous polymer matrix of protein. CHW are known by different names in the literature such as nanocrystals, microcrystallites, nanofibrils, nanofibres or nanoparticles. Unlike cellulose whiskers which can only be prepared by strong sulphuric acid [41, 42]CHW are prepared using hydrochloric acid. Marchessault et al [43]was the first to report a procedure for the preparation of whiskers from chitin. In their report, purified chitin was acid hydrolysed using $2.5 \mathrm{~N}$ hydrochloric acid solutions under reflux for 60 minutes; the excess acid was gradually decanted, after which distilled water was added to obtain a suspension. They observed that acid hydrolyzed chitin dispersed into rodlike particles. Following their report CHW have been produced from different sources of chitin. These are crab shells [9, 15-17, 44-48], riftia tubes [11], shrimp shells [13, 30, 49-54] and squid pen [55]. Recently Ifuku et al., [56] prepared chitin nanofibres from prawn shell by simple grinding without acidic chemicals. The nanofibres were $10-20 \mathrm{~nm}$ in width.

\subsubsection{Preparation of Chitin Whiskers}

In their approach in preparing CHW, Li et al., [9] and Revol et al., [44], purified chitin was hydrolyzed by $3 \mathrm{~N}$ $\mathrm{HCl}$ at a temperature of $104{ }^{\circ} \mathrm{C}$ for $1.5 \mathrm{~h}$, then after acid hydrolysis the suspensions were diluted with deionised water, followed by centrifugation and decanting of the supernatant. This process was repeated until a colloidal state of the suspensions was observed. The crystallites were rod-like particles with average lengths and widths of $200 \pm 20 \mathrm{~nm}$ and $8 \pm 1 \mathrm{~nm}$ respectively.
CHW suspensions are reported to exhibit a colloidal behaviour. This behaviour was attributed to the presence of the positive charges $\left(\mathrm{NH}_{3}^{+}\right)$on the surface of the CHW which was due to protonation of the amino groups of chitin in the acidic conditions [43]. Some times protonation of the amino groups is incomplete on all the CHW particles there by resulting in aggregate particles [46].

During the process of preparing nanocrystals from polymer materials, both the amorphous and the crystalline phases can be hydrolysed when strong acids are applied [57]. Due to the closed packed molecular chains in the crystalline domains of chitin, boiling chitin in $\mathrm{HCl}$ dissolves the amorphous phase [58] earlier than the crystalline phase. It has also been shown that the ether and the amide linkages can be broken [59]. Two important parameters that determine the particle size and yield are hydrolysis time and the concentration of $\mathrm{HCl}$. Most researchers use between 2.5 to $3 \mathrm{~N}$ at a time frame of between 1.5 to $6 \mathrm{~h}$ irrespective of the source of chitin; Crab [9, 15,], riftia tubes [11], shrimp shells [13, $30,49,51-54$ ] and squid pen chitin [55]. Increases in the concentration of $\mathrm{HCl}$ have shown to significantly destroy the chitin crystals even to the point of completely dissolving it at $8.5 \mathrm{~N}[43,59]$.

Following the successful preparation of cellulose nanocrystals by Montanari et al., [61] and nanofibers, Saito et al., [58] using TEMPO-mediated oxidation (2,2,6,6-tetramethylpiperidine-1-oxyl radical mediated oxidation), Fan et al., [60] successfully used this method to prepare chitin nanofibres and chitin nanocrystals. The addition of $5.0 \mathrm{mmol} / \mathrm{g}$ of $\mathrm{NaClO}$ per gram of chitin in the oxidation gave an optimum condition for the preparation of mostly individualized (Figure3C) nanocrystals whose length and width were 340 and $8 \mathrm{~nm}$ respectively. After alkaline treatment of CHW, Phongying et al., [54] observed that the packing structure of the CHW changed from tight crystalline to amorphous. TEM images showed that the alkaline treated CHW are a fibrous form (Figure3 A and B). Combining the results obtained from WAXD, SEM and FTIR they concluded that CHW in alkaline solution changes to form a chitosan nanoscaffold. Detailed information of CHW prepared from different sources of chitins is summarized in Table 2.

\section{MECHANICAL PROPERTIES OF CHW BASED NANOCOMPOSITES}

Different methods have been employed for the preparation of CHW based nanocomposites. They are casting and evaporating [30, 52, 55], freeze-drying and hot-pressing $[11,16]$ and polymer grafting [17]. 


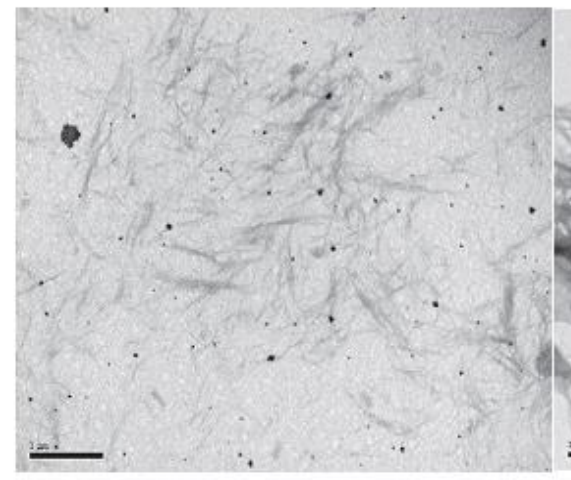

A

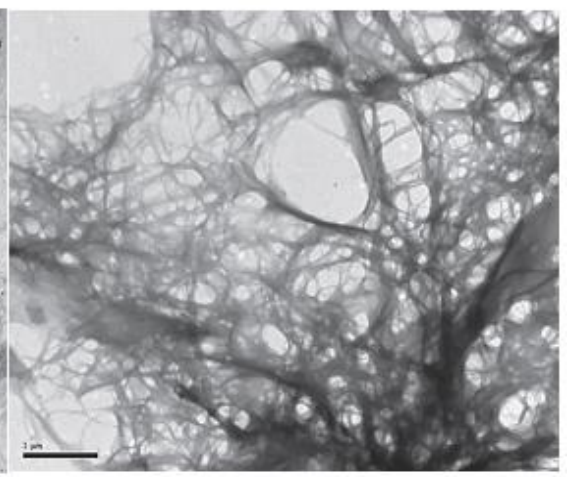

B

TEMPO-oxidized chitins (the amount of $\mathrm{NaClO}$ added)

$(2.5 \mathrm{mmol} / \mathrm{g})$

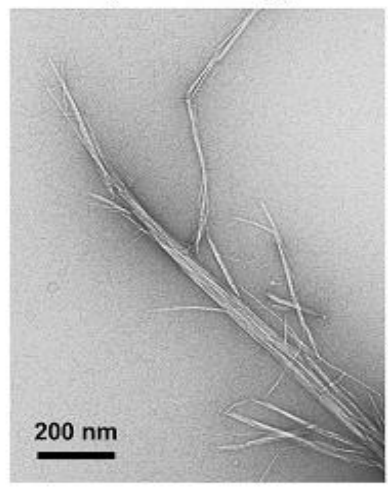

$(5.0 \mathrm{mmol} / \mathrm{g})$

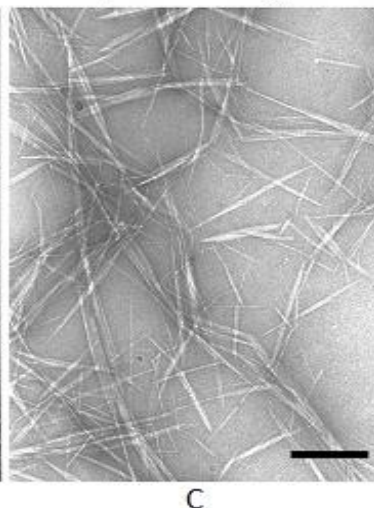

$(10.0 \mathrm{mmol} / \mathrm{g})$

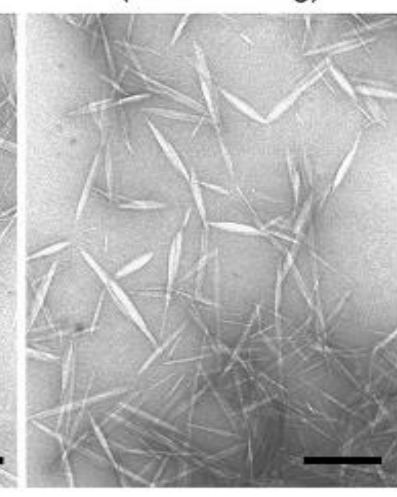

Figure 3: TEM micrographs of (a) CHW in water, (b) CHW after treatment in Alkaline [54] (C) TEM imaging of TEMPO-oxidized chitin nanocrystals prepared under different conditions [60].

Table 3 - Sizes, preparation time and temperature of CHW prepared from different sources.

\begin{tabular}{|c|c|c|c|c|c|}
\hline Source of chitin & Width (nm) & Length (nm) & Time of hydrolysis (h) & Temperature $\left({ }^{\circ} \mathrm{C}\right)$ & Reference \\
\hline Shrimp & $12-65$ & $231-969$ & 6 & 120 & {$[52]$} \\
\hline Shrimp & $18-40$ & $200-500$ & 3 & 105 & {$[30]$} \\
\hline Shrimp & $5-70$ & $150-800$ & 1.5 & 104 & [54] \\
\hline Shrimp & $8-74$ & $180-820$ & 6 & 104 & [49] \\
\hline Shrimp & $10-15$ & $200-500$ & 1.5 & 104 & [13] \\
\hline Shrimp & $8-73$ & $110-975$ & 3 & 104 & [51] \\
\hline Crab & $27-35$ & $203-277$ & 6 & 120 & {$[46]$} \\
\hline Crab & $\sim 20$ & $\sim 240$ & 1.5 & 104 & {$[17]$} \\
\hline Crab & $\sim 15$ & $\sim 240$ & 1.5 & 104 & {$[47]$} \\
\hline Crab & $10-80$ & $100-650$ & 1.5 & 104 & [15] \\
\hline Crab & $6-8$ & $50-300$ & 1 & 104 & {$[44]$} \\
\hline Squid pen & $\sim 10$ & $50-300$ & 1.5 & 104 & [55] \\
\hline Squid pen & $7-70$ & $150-800$ & 1.5 & 104 & [50] \\
\hline Riftia tube & 18 & $500-1000$ & 1.5 & 104 & [11] \\
\hline
\end{tabular}

When preparing nanocomposites the technique to be used must take into account the properties of the whiskers and the matrix in addition to the desired end properties of the composite. Inaba et al., [62] used starch (potato, sweet potato, kudzu, corn, wheat and mung bean) gels to form composites with chitin and collagen as fillers. The results showed that there was an in increase in the gel hardness between $90-120 \%$ for potato, sweet potato and wheat and an increase of between 150-300\% for corn as starch concentration was increased. Similarly there was an increase between 90-300 \% in cohesiveness and adhesiveness as starch concentration 
increased. They attributed the increase in gel hardness to complex factors, among which are filler particle size, nature of the gel matrix, starch retrogression rate and swelling nature of the particle.

Feng et al., [17] formed a chitin whisker-graftpolycaprolactone (PLC) composite using different mixtures of chitin and polycaprolactone monomer. They reported an increase in tensile strength and breaking strain while Young's modulus decreased as the PCL content was increased. $\beta$-chitin/poly(vinyl alcohol) (PVA) composite films at different ratios were formed by Peesan et al., [63]. The tensile strength was found to increase from 0.7 to $5.1 \mathrm{MPa}$ with an increase in $\beta$-chitin content, compared to pure $\beta$-chitin or PVA. The percentage elongation at break decreased from $165.2 \%$ to $2.9 \%$ while the behaviour of the composite became brittle as the $\beta$-chitin content increased. Instead of using $\beta$-chitin, Junkasemet al. [52] and Junkasemet al.,[53] used $\alpha$-chitin as reinforcement with PVA; their result showed better mechanical properties than Peesan et al., [63].

Nair and Dufresne, [47] carried out chemical modification of crab shell CHW using three different reagents; namely phenyl isocyanate (PI), alkenyl succinic anhydride (ASA) and 3-isopropenyl-, $\alpha, \alpha^{\prime}$-dimethylbenzyl isocyanate (TMI). They investigated the effect of the incorporation of these materials into a natural rubber matrix. PI and ASA were used to improve the quality of the interface between the natural rubber matrix and the CHW, while TMI helped the CHW to copolymerize with the natural rubber matrix. The chemical modification resulted in the reduction of the mechanical properties. They concluded that this "could be due to the partial or total destruction of the three-dimensional network of CHW assumed to be present in the unmodified composites."

Calcium alginate yarns and calcium alginate nanocomposite yarns containing 0.05-2.00 \% w/w CHW were both prepared using a wet spinning process [30]. An increase in the tenacity of the hybrid was found at $0.015 \% \mathrm{w} / \mathrm{w}$ of whiskers, reaching a maximum at 0.15 $\% \mathrm{w} / \mathrm{w}$, followed by a decrease. The same trend was observed for the elongation at break. A maximum elongation at break was observed at $0.10 \% \mathrm{w} / \mathrm{w}$. They concluded that the initial rise in tenacity and elongation was due to electrostatic interactions and intermolecular hydrogen bonding between molecules and the CHW at low whiskers content, while the decrease in tenacity and elongation was attributed to the aggregation of the whiskers.

He and $\mathrm{Ma}$, [64]prepared cellulose/chitin composites using a high wet method (where the spinning solution preparation method and spinning technique will have determining influence on the final properties (i.e., mechanical property and wet modulus)). The result shows better mechanical properties when compared with crabyon fiber and normal viscose filaments. Also Zhang et al.,[65] successfully blended chitin/cellulose using two different coagulating systems (immersed in 5 wt $\% \mathrm{H}_{2} \mathrm{SO}_{4}$ for 5 minutes, and subsequently $10 \mathrm{wt} \%$ glycerine for 10 minutes (H membranes) another immersed in $5 \mathrm{wt} \% \mathrm{CaCl}_{2}$, and follow the earlier steps ( $\mathrm{C}$ membranes)) to compare mechanical properties. The tensile strength of H-membranes, in both wet and dry states, increased with an increase in chitin content and decreased with an increase in chitin content for the $\mathrm{C}$ membranes. Conversely the breaking elongation for $\mathrm{C}$ membranes was much higher than that for H-membranes for both wet and dry specimens, as the chitin content increased. These results confirmed that there is a relatively weak interaction between cellulose and chitin for the $\mathrm{C}$ blend membrane, caused by an addition of chitin, and a strong interaction between cellulose and chitin in the $\mathrm{H}$ blends.

Four different methods of chitin film preparation were studied by Yusofet al., [66]. Depending on the method, the Young's modulus varied between 1.2 and $3.7 \mathrm{GPa}$ while the tensile strength was between 38.3 to $77.2 \mathrm{MPa}$ and the \% strain between 4.7 and $21.3 \%$. Ifuku et al.,[56] reported a Young's modulus of $2.5 \mathrm{GPa}$ and a tensile strength of $\sim 40 \mathrm{MPa}$ for chitin film. The Young's modulus of chitin reinforced (meth) acrylic resin varied between 1.2 and $\sim 5 \mathrm{GPa}$ while the tensile strength was between $\sim 30$ and $\sim 70 \mathrm{MPa}$ depending on the number of the repeating units of acrylic acid resin. The mechanical properties of CHW reinforced poly vinyl alcohol (PVA) composites films with or without heat treatment have been shown to have improved compared to the original matrix [50]. The tensile strength was between $\sim 60$ and $\sim 83 \mathrm{MPa}$ while the \% strain continue to decrease from $14.7 \%$ for pure PVA film to $5.5 \%$ for composite film having 29.6 wt \% CHW

Two different techniques; freeze-drying and hot pressing and casting and evaporating were employed by Nair and Dufresne, [48] to obtain CHW reinforced natural rubber. The result shows clear evidence of the dependence of the properties on the technique used. The modulus for unvulcanized evaporated samples was higher than those of vulcanized evaporated ones, while the unvulcanized hot pressed composites were the least. Nanosized CHW forms a 3-D rigid network in the evaporated technique method; Table 3 shows a summary of the properties at different CHW content.

When soy protein was reinforced with CHW [15] there was an increase in modulus and tensile strength from 26.4 to $158 \mathrm{MPa}$ and 3.3 to $8.4 \mathrm{MPa}$ respectively as CHW content was increased from $0-20$ wt $\%$, while the elongation at break decreased from $205 \%$ to $29 \%$. Above 20 wt \% CHW, the mechanical properties 
decrease. The tensile strength of $\mathrm{CHW}$ reinforced chitosan increases from the initial $\sim 65 \mathrm{MPa}$ for chitosan to $\sim 84 \mathrm{MPa}$ at $\mathrm{CHW}$ content of $2.96 \%$. Subsequent addition of CHW did not show any significant decrease up to $29.6 \%$ content. The percentage elongation at break decreases from $\sim 12 \%$ for chitosan and level up at CHW greater or equal to $2.96 \%$ [49]. The same behavior was observed when poly(vinyl alcohol) was used as the matrix [50].

Figure 4 shows the normalized mechanical properties of CHW reinforced polymers composites at different CHW content. The properties of pure polycaprolactone were obtained from Azevodo and Reis, [67]. From the figure there is a clear trend of decrease in strain at break as CHW increases. Most authors agreed that the initial increase in tensile strength and Young's modulus up to a certain filler loading is an indication of strong interactions between whiskers and the matrix. These interactions restrict the motion of the matrix leading to better properties.

From Figure4B, tensile strength continues to increase subject to CHW content $\leq 20 \%$. At CHW content $>20 \%$ the tensile strength either decreases or there is no significant increase. Similarly, the Young's modulus increases up to between 20 and $25 \%$ CHW, after which it decreases. There is a continuous decrease in strain as CHW increases. In conclusion the tensile strength and
Young modulus increases subject to $\mathrm{CHW}<25 \%$ content.

PAA composites have shown better mechanical properties compared with the neat polymer. Faturechi et al, [68] investigated the linear elastic and nonlinear hyperelastic mechanical properties of alkaline processed gelatine hydrogels at various PAA content for tissue engineering applications. The result shows that the addition of $10 \mathrm{wt} \%$ PAA in Gel hydrogels increases the modulus and maximum tensile strength. At PAA $>10 \mathrm{wt}$ $\%$ contents a weaker mechanical strength and lower nonlinear behaviour of composite hydrogel was observed. Figure5 shows the graphical representation of their result.

Similarly, Faghihi et al., [69] investigated the linear and nonlinear mechanical behaviour of graphene oxide/poly(acrylic acid)/gelatine (GO/PAA/Gel) composite hydrogels having different graphene oxide nanosheet (GONS). Irrespective of the GONS content, the hydrogels showed a near linear mechanical behaviour. The hydrogels with relatively lower content of GONS $(<0.3$ wt \%)have enhanced mechanical properties compared with those with higher content of GONS ( $>0.3$ wt \%). On addition of $0.3 \mathrm{wt} \%$ GONS, both tensile strength and strain of GO (0.0 wt \%)/PAA/Gel increased by $71 \%$ and $83 \%$ respectively. The increase was attributed to hydrogen and possible covalent bonds between GONS and polymer chains.

Table 3: Mechanical properties of CHW filled natural rubber using data obtained from tensile tests: Tensile modulus $(E)$, conventional rubber modulus $\left(E_{100 \%}\right)$, stress at break $\left(\sigma_{B}\right)$, and elongation at break $\left(\varepsilon_{B}\right)$ [48].

\begin{tabular}{|c|c|c|c|c|c|c|c|}
\hline & & & & $\begin{array}{l}\sigma_{\mathrm{B}} \\
(\mathrm{MPa})\end{array}$ & & $\begin{array}{l}\varepsilon \text { в } \\
(\%)\end{array}$ & \\
\hline Sample & Processing Technique & $E(\mathrm{MPa})$ & $E_{100 \%}(\mathrm{MPa})$ & True & nominal & True & nominal \\
\hline NRev & Water evaporation & 1.7 & 1.8 & 25.5 & 2.1 & 248 & 1099 \\
\hline $\mathrm{NCH} 2 \mathrm{ev}$ & & 5.6 & 2.5 & 21.7 & 2.6 & 213 & 740 \\
\hline NCH5ev & & 17.8 & 5 & 25 & 3.7 & 192 & 583 \\
\hline NCH10ev & & - & - & - & - & - & - \\
\hline NCH15ev & & 127 & 17 & 29.7 & 7.9 & 133 & 276 \\
\hline NCH20ev & & 229 & 23.9 & 9.8 & 126 & 126 & 252 \\
\hline PNRev & water evaporation & 1.6 & 1.6 & 395 & 11.8 & 351 & 3252 \\
\hline PCH2ev & & 2.5 & 2.1 & 388 & 13.7 & 334 & 2728 \\
\hline PCH5ev & & - & - & - & - & - & - \\
\hline PCH10ev & & 25.9 & 6.8 & 178 & 10.5 & 283 & 1590 \\
\hline PCH15ev & & 52.8 & 11.4 & 128 & 9.4 & 261 & 1265 \\
\hline PCH20ev & & 111 & 15.3 & 20.5 & 5.6 & 130 & 268 \\
\hline NRL & $\begin{array}{l}\text { Freeze drying and hot- } \\
\text { pressing }\end{array}$ & 1.1 & 0.71 & 41.6 & 3.4 & 252 & 1137 \\
\hline NCH2L & & 1.4 & 0.99 & 5.9 & 1 & 176 & 483 \\
\hline NCH5L & & 2.1 & 1.7 & 15.5 & 2.7 & 175 & 475 \\
\hline NCH10L & & 4.6 & 3.4 & 21.7 & 4.4 & 160 & 397 \\
\hline NCH15L & & 8.7 & 7.2 & 62.7 & 10.5 & 179 & 498 \\
\hline NCH20L & & 10.2 & 9.4 & 83.9 & 14.4 & 176 & 482 \\
\hline
\end{tabular}



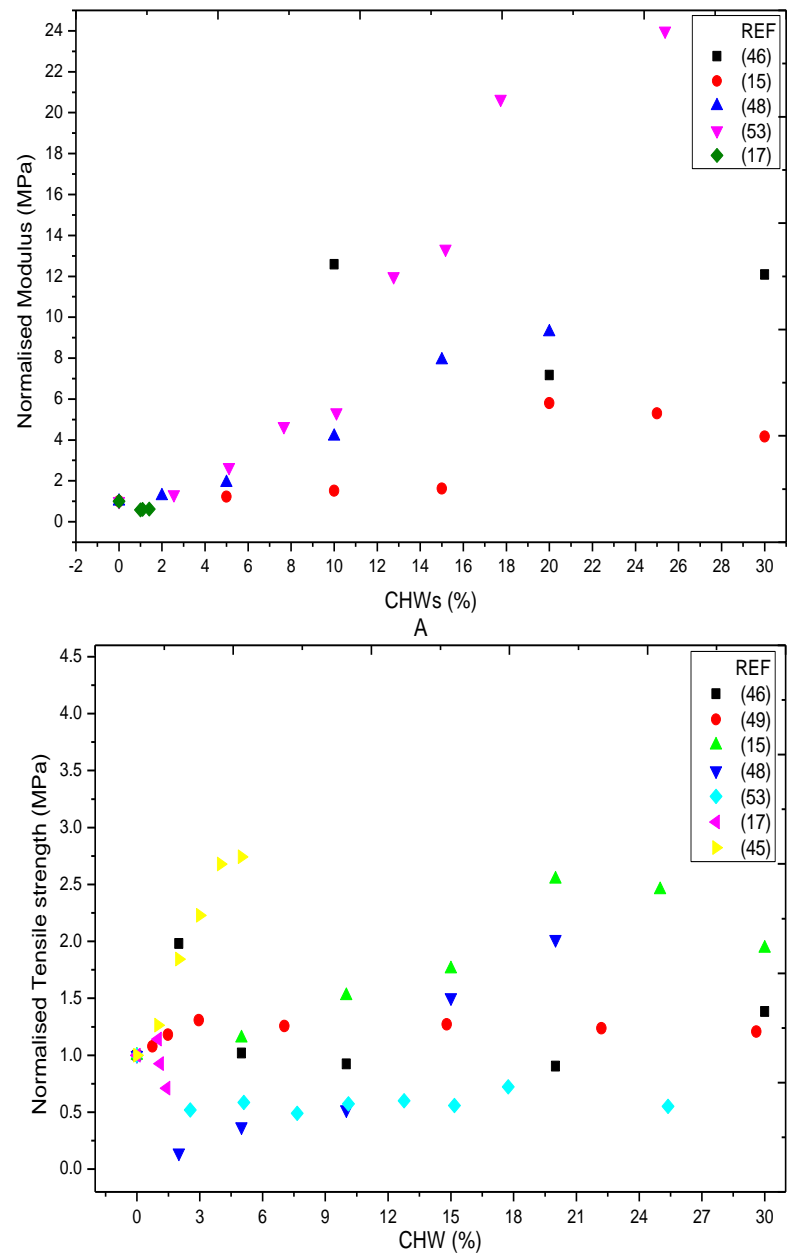

(B)

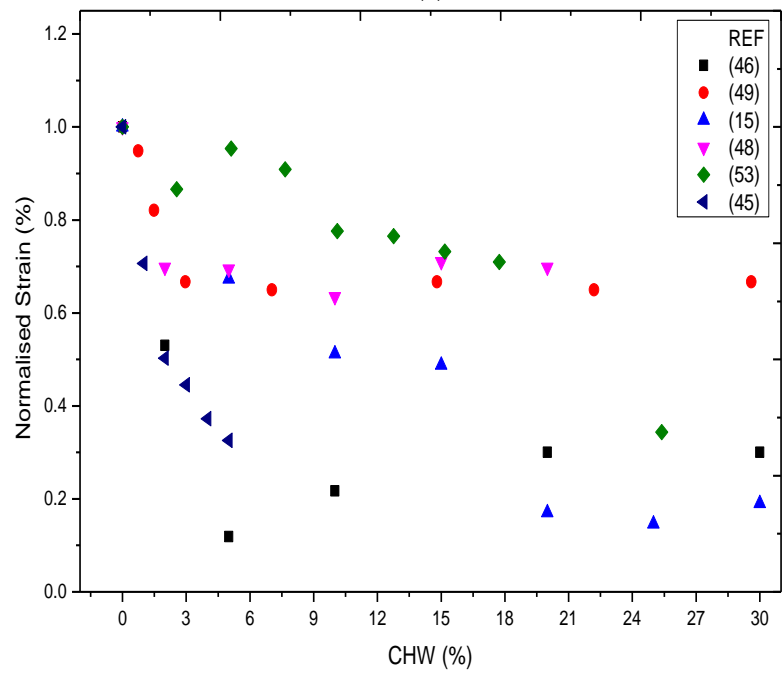

(C)

Figure 4- Normalised (against matrix) properties of CHW reinforced composites at different percentage laoding of CHW (A) Modulus, (B) tensile strength and $(C)$ strain at break.

The lower content of GONS (0.3 wt \%) was well dispersed in the polymer matrix which would enhance the intermolecular interactions between the matrix and the filler. At higher amount of GONS (0.5 wt \%) large agglomeration may form there by weakening the interfacial interactions. Figure 6 shows the the tensile strength and failure strain of the composites.

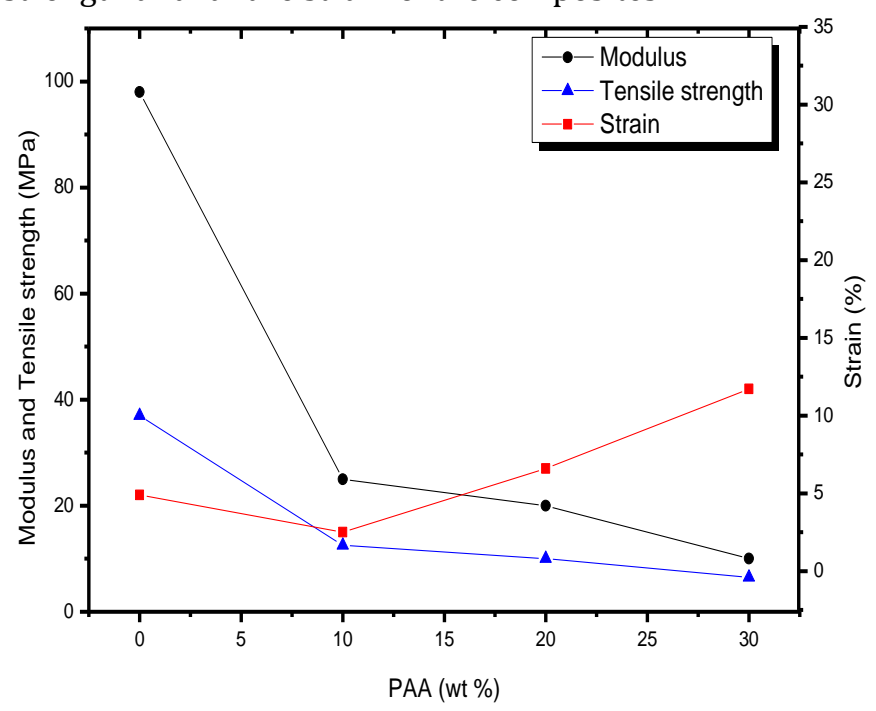

Figure5- Mechanical properties of gelatine gel reinforced PAA. [68](Modified).

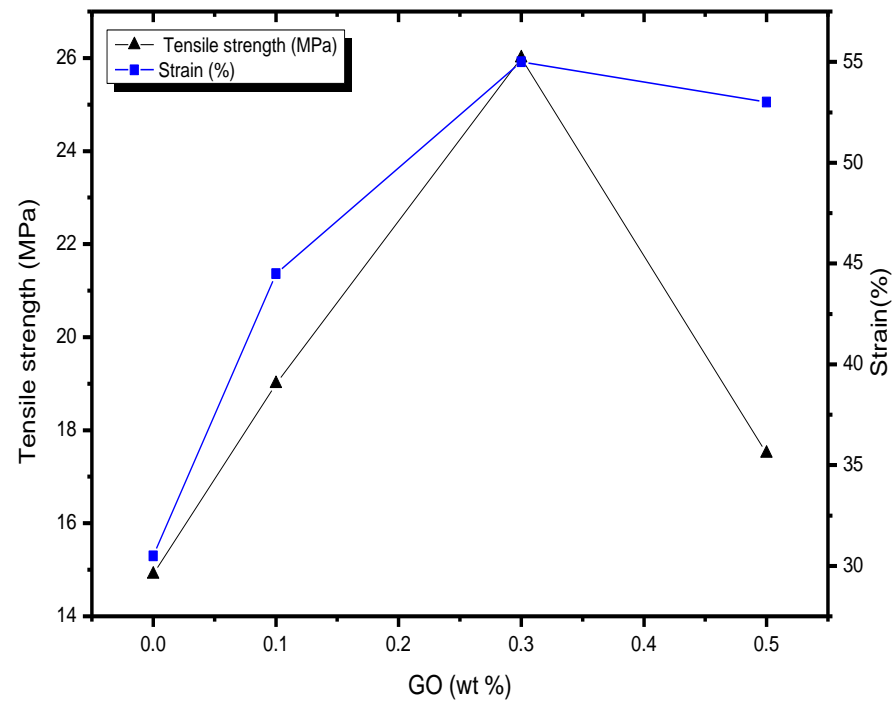

Figure6- Tensile strength (a) and tensile strain (b) of composite hydrogels having different graphene oxide nanosheet (GONS) content [69] (Modified).

Ironically cross-linked polyelectrolyte complex (PEC) membranes of cationic chitosan and anionic poly(acrylic acid) were synthesized by Smitha et al. [70]. Composites of chitosan (CS) and PAAc were made at different weight ratios: $90 / 10,80 / 20,70 / 30,60 / 40,50 / 50$ and 25/75 (CS/PAAc). The membranes were post-treated to enable the formation of the polyelectrolyte complex. The 50/50 composite exhibited low methanol permeability (3.9 x10$8 \mathrm{~cm}^{2} / \mathrm{s}$ ), the best physicomechanical properties and comparatively high proton conductivity $\left(0.038{\mathrm{~S} . \mathrm{cm}^{-1}}^{-1}\right)$. The tensile strength and elongation at break and other properties of the composites in the dry state are given in Table 5. From the table, increase in the CS weight causes 
an increase in the tensile strength and a reduction in the elongation at break of the composite membranes. The enhancement was attributed to the ionic-cross-linking of the polyelectrolyte membranes.

\section{THERMAL PROPERTIES}

Engineering materials are subjected to changes in temperature leading to thermal expansion, melting, freezing, glass transition temperature etc. Their behaviour under these conditions determines their potential applications. Therefore the study of the thermal properties of hybrid biomaterial composites is very important. Different composites of CHW reinforced poly (vinyl alcohol) were tested for thermal properties [52, 63]. The glass transition temperatures of the composite films were found to increase with increase in CHW content, while the melting temperatures tended to shift towards lower values. As a mark of thermal stability, thermogrametric loss in weight upon heating decreased as CHW increased and the value was found to be between those of the pure components. Notwithstanding, improvement in thermal stability is subject to having a CHW content less than $10 \%[46,49,50]$.

Some research reports that the onset decomposition temperature increased with increase in CHW content [16]. Composite films prepared by casting and evaporation from poly(styrene-co-butyl acrylate) and poly(S-co-BuA) showed an increase in storage modulus when the temperature was greater than the glass transition temperature of the matrix. At filler loadings less than $10 \mathrm{wt}$ \% the mechanical properties showed no improvement but increased to $\sim 2 \mathrm{GPa}$ (from $1 \mathrm{GPa}$ for pure matrix) at $20 \mathrm{wt}$. \% while the addition of $\mathrm{CHW}$ did not affect the glass transition temperature of the composites [55]. Feng et al.,[17] used dynamic mechanical analysis (DMA) to determine the $\alpha$-relaxation temperature of CHW-g- polycarprolactone (PCL) copolymer nanocomposites.

Table 5-Sorption characteristics, tensile strength and elongation, ion exchange capacity and methanol permeability of composites [70](Modified).

\begin{tabular}{|c|c|c|c|c|c|c|}
\hline membrane & $\begin{array}{l}\% \text { water } \\
\text { uptake }\end{array}$ & $\begin{array}{l}\% \text { methanol } \\
\text { uptake }\end{array}$ & $\begin{array}{c}\text { Tensile } \\
\text { strength } \\
(\mathrm{MPa})\end{array}$ & $\begin{array}{l}\% \text { elongation } \\
\text { at break }\end{array}$ & $\begin{array}{c}\text { ion exchange } \\
\text { capacity } \\
\text { (mequiv/g) }\end{array}$ & $\begin{array}{c}\text { Methanol } \\
\text { permeabilitya } \\
\left(10^{-8} \mathrm{~cm}^{2} / \mathrm{s}\right)\end{array}$ \\
\hline PAAc & B & 0.08 & 8.78 & 8 & 0.86 & D \\
\hline PEC25/75 & 54 & 0.63 & 21.81 & 7.3 & 1.24 & 4.8 \\
\hline PEC50/50 & 26 & 1.06 & 26.10 & 4 & 1.06 & 3.9 \\
\hline PEC60/40 & 35 & 1.2 & 24.11 & 5 & 1.18 & 4.1 \\
\hline PEC70/30 & 42 & 1.28 & 23.91 & 7 & 1.22 & 4.6 \\
\hline PEC80/20 & 80 & 1.29 & 22.81 & 7.5 & 1.16 & 8.2 \\
\hline PEC90/10 & 139 & 1.41 & 20.29 & 8 & 0.94 & 8.7 \\
\hline CS & $\mathrm{c}$ & 0.39 & 18.07 & 4 & 0.91 & D \\
\hline
\end{tabular}

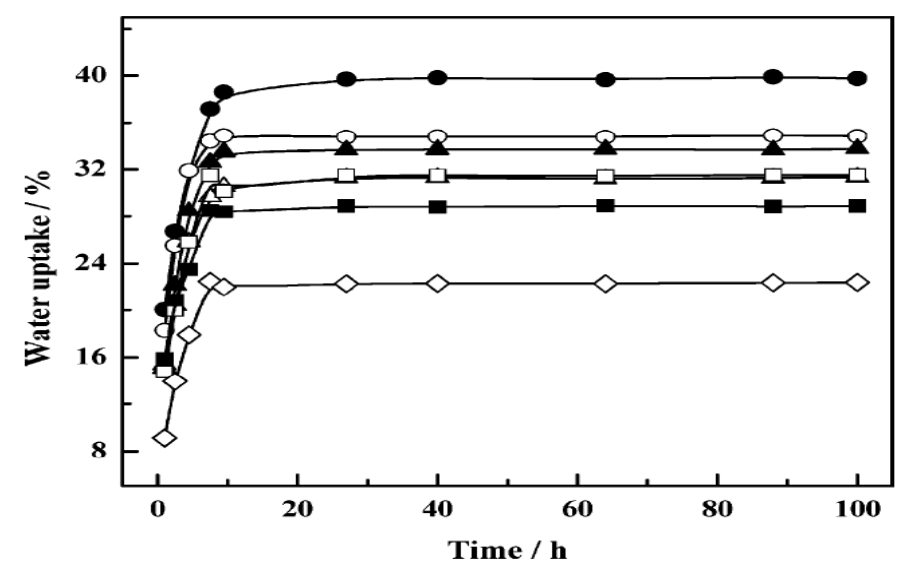

(A)

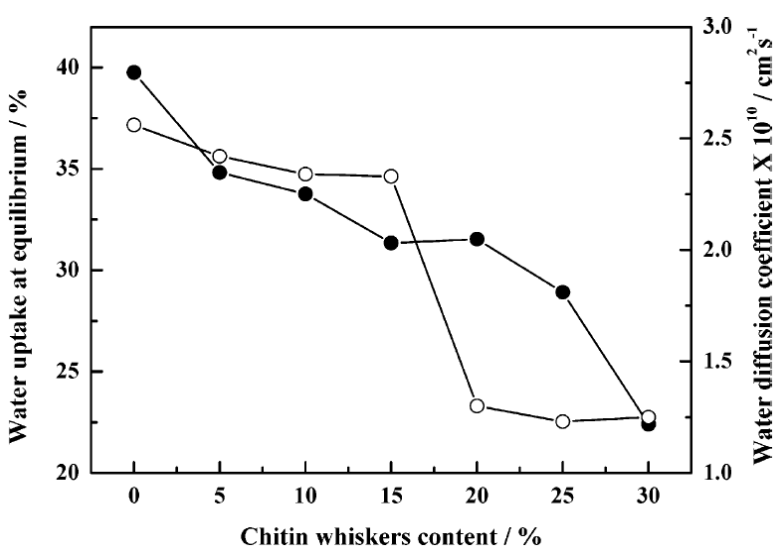

(B)

Figure 7: Water uptake at equilibrium of glycerol soy protein isolate sheet ( $\bullet$ ) and SPI/CHW composites of SPI-5(o),

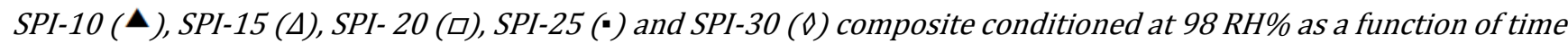
(A)and water uptake at equilibrium (•) and water diffusion coefficient (o) as a function of chitin whiskers content for composites conditioned at $98 \% R H(B)$ [15]. 


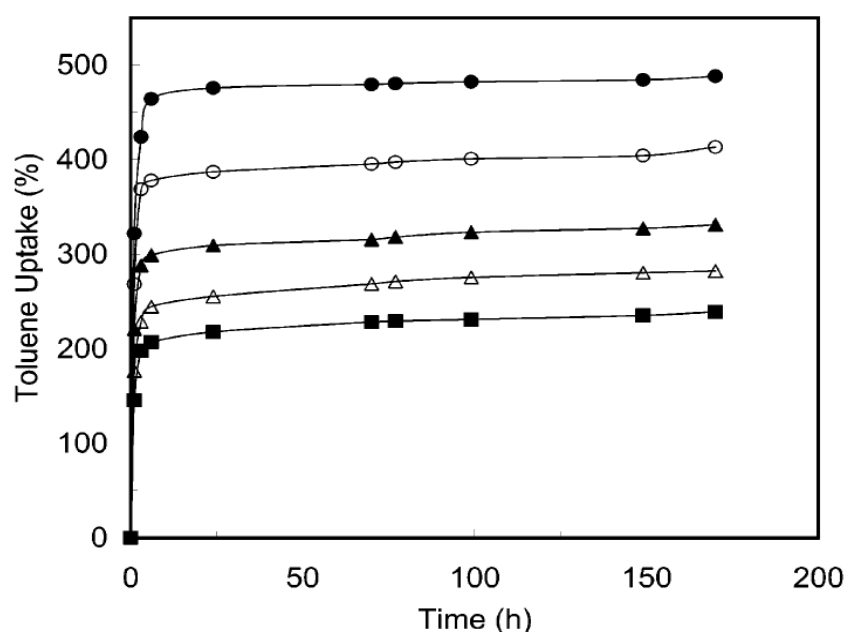

(A)

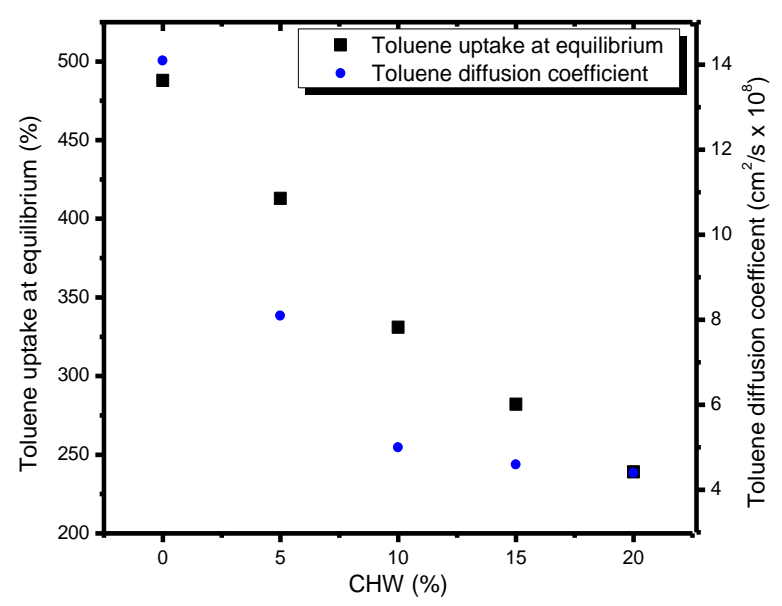

(B)

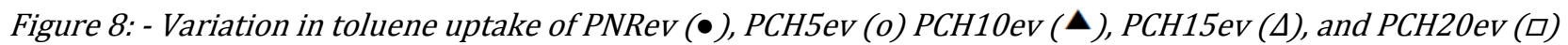
samples as a function of time at room temperature $\left(25^{\circ} \mathrm{C}\right)(\mathrm{A})$ and toluene uptake at equilibrium and toluene diffusion coefficients in CHW/Vulcanized NR Composites immersed in toluene (B). [47]

The results showed an increase in the glass transition temperature (from -32 to $-39.6{ }^{\circ} \mathrm{C}$ ) as $\mathrm{CHW}$ content increased (from 0.99 to $1.141 \%$ ) an indication of a gradual decrease in the segmental mobility of PCL while the melting temperature and enthalpy of fusion remained relatively the same $\left(\sim 56{ }^{\circ} \mathrm{C}\right.$ and $\sim 65 \mathrm{~J} / \mathrm{g}$ respectively) within the CHW content (0.99 to $1.141 \%$ ) range.

\section{OTHER PROPERTIES OF CHITIN}

Austin, [71]wasthe first to publish an extensive study on chitin solubility. This work determined solubility parameters $(\delta)$ (a numerical value based on the cohesive energy densities) for different solvents in lithium Chloride (LiCl). Solubility parameters of 10.8 for dimethyl acetamide and 11.3 for N-methyl pyrrolidinonewere reported. Due to its intermolecular hydrogen bonding chitin is insoluble in most organic solvents but readily soluble in concentrated $\mathrm{HCl}, \mathrm{H}_{2} \mathrm{SO}_{4}$ and $\mathrm{H}_{3} \mathrm{PO}_{4}$ and few other organic acid such as formic, dichloroacetic and trichloroaceticacids and strong polar solvents such as $\mathrm{LiCl}$, dimethylacetamide (DMAc) and Nmethyl-2-pyrrolidone (NMP) $[71,72]$. The dissolution of chitin in mineral acid is accompanied by degradation. To achieve the desired solubility the degree of deacetylation and the concentration ratio between acid and chitosan must be taken into consideration. Full solubility is achieved at $\geq 85 \%$ deacetylation [73]. A reproducible method for obtaining water-soluble chitin and the relationship between solubility and degree of deacetylation of chitin were studied [74]. The regenerated chitin, isolated at low temperature from an alkali chitin solution left at $25{ }^{\circ} \mathrm{C}$ for 48 to 77 hours, showed a very good solubility in water at $0{ }^{\circ} \mathrm{C}$. Kubota and Eguchi, [75] showed that alkali-chitin exhibited a lower critical solubility temperature of about $30^{\circ} \mathrm{C}$.

Water swelling properties of CHW reinforced soy protein isolate (SPI) composites (using glycerol as plasticizer) were investigated by $\mathrm{Lu}$ et al.,[15]. At $25{ }^{\circ} \mathrm{C}$ the water uptake of SPI film was $\sim 40 \%$ that of CHW/SPI decreased as CHW content increased. For example, 20, 25 and 30 wt \% CHW content had $29 \%, \sim 28 \%$ and $~ 23 \%$ water uptake suggesting an increase of water resistance as CHW content increased. Figure7 shows the water uptake at equilibrium of $\mathrm{CHW}$ reinforced soy protein isolate (SPI) composites and the time taken to obtain maximum water uptake.

Similar results were obtained when $\alpha$-chitin whiskerreinforced poly (vinyl alcohol) composite films with or without heat treatment were investigated by Sriupayoet al.,[50]. The uptake of toluene (Figure8 A and B) by vulcanized natural rubber/CHW composites was investigated by Nair and Dufresne, [47]. There was an initial rapid uptake of toluene by all composites within $5 \mathrm{~h}$ and there was a decrease in sorption rate. Neat vulcanized natural rubber uptake of toluene was $488 \%$, which decreased to $413,331,282$ and $239 \%$ at 5, 10, 15 and $20 \%$ loading of CHW. The diffusion coefficient of toluene of neat VNR $\left(14.1 \times 10^{-8} \mathrm{~cm}^{2} \mathrm{~s}^{-1}\right)$ decreased with increasing loading of CHW to $4.4 \times 10^{-8} \mathrm{~cm}^{2} \mathrm{~s}^{-1}$ at $20 \%$ loading. Nair and Dufresne attributed this to the increase in stiffness of the chitin network and interactions between VNR and CHW with increased CHW loading.

\section{6. $\mathrm{CaCO}_{3} / \mathrm{CHW}$ HYBRID COMPOSITES}

Biomineralization is a process in which living organisms produce inorganic/organic hybrids. The production of this hybrid under different conditions has received attention in recent years. The essence of producing this 
biomineral is to have a complex but environmentally friendly morphology and as well as better mechanical properties. However the understanding of these hybrids' development processes is still a subject of research. Biominerals, like the nacre of shell, have high optical and mechanical properties; these properties are closely related to their hierarchically- ordered structures [76]. It has been reported that the exoskeleton of the crayfish is composed of about 50:50 wt \% of $\mathrm{CaCO}_{3}$ and organic macromolecules such as chitin and proteins. Calcium carbonate polymorphs (calcite, vaterite or aragonite) are some of the mineral phases formed when an insoluble polymer with the help of a soluble agent of polymeric anions is induced on a substrate $[77,78]$. The production of these polymorphs (calcite, aragonite, and vaterite) might be influenced by the conditions of precipitation and the presence of impurities in an aqueous solution. Of the three polymorphs, calcite is the most thermodynamically stable under ambient conditions while the least stable is vaterite. A variety of $\mathrm{CaCO}_{3}$ crystal/chitin or chitosan based hybrid materials have been reported, some will be reviewed here.

Oriented chitin films as templates were used for $\mathrm{CaCO}_{3}$ crystallization in the presence of poly(acrylic acid), (PAA) [79]. At about 10 hours after immerging the films in the crystallization solution (ammonium carbonate vapour was slowly diffused into aqueous solution of calcium chloride) at a temperature of $5{ }^{\circ} \mathrm{C}$ small rods of about $8 \mu \mathrm{m}$ in length of $\mathrm{CaCO}_{3}$ crystals were observed. The rod-like $\mathrm{CaCO}_{3}$ crystals (Figure9) increase in length to $80 \mu \mathrm{m}$ after 50 hours of immersion. The diameter of the rod was between 10 and $30 \mu \mathrm{m}$. At $30{ }^{\circ} \mathrm{C}$ similar crystallization behaviour was observed. The calcite polymorph was confirmed by FTIR. Calcium carbonate was precipitated on three insoluble polymer matrices (chitin, cellulose and chitosan). Their derivatives $(\mathrm{OH}$, and $\mathrm{NH}_{2}$ were synthesized by the acetylation of hydroxyl groups following the $\mathrm{N}$-phthaloylation of the amino group of chitosan and the acetylation of chitin respectively to prevent proton donation (see Figure10) in the presence of PAA [77].
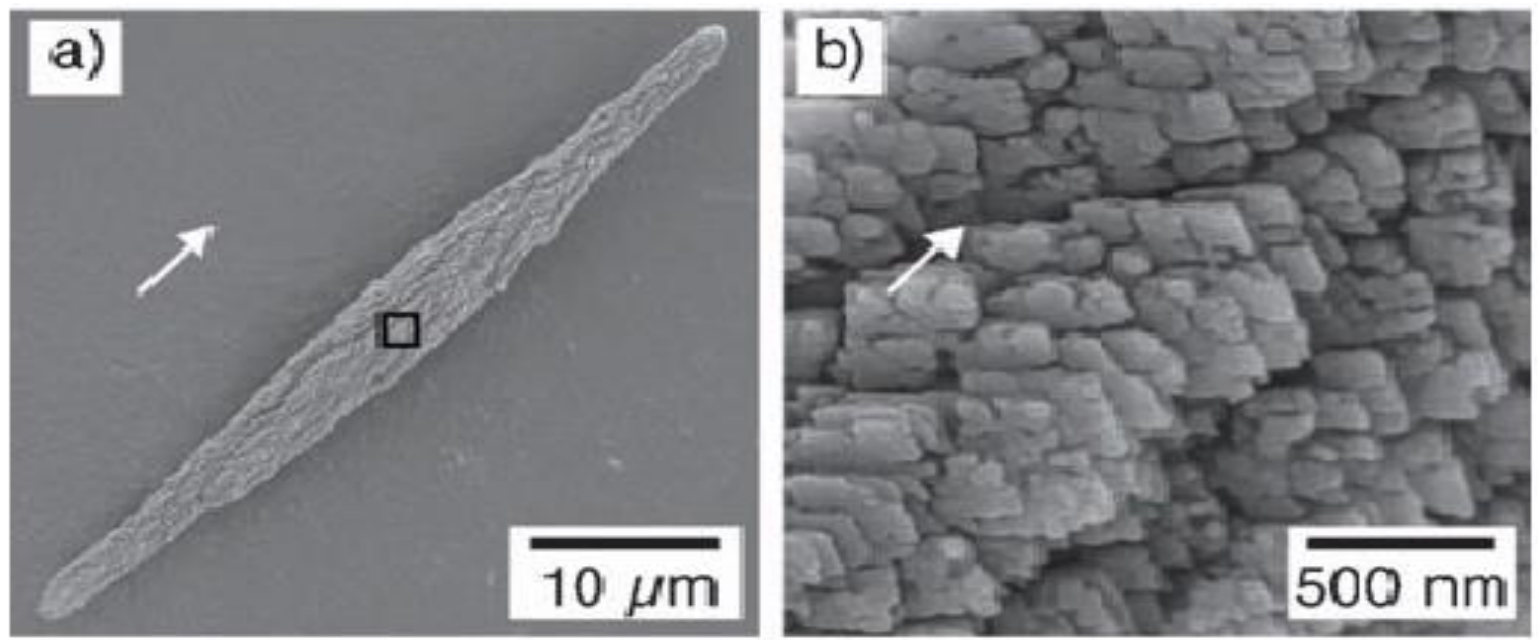

Figure9 - SEM image of the rod shape of the isolated crystal (a) and magnified image of the square area on the crystal surface in (b) [79].

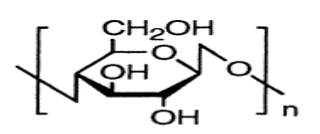

1a: cellulose

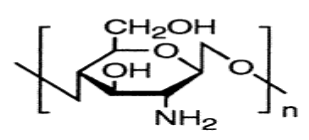

2a: chitosan

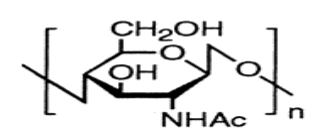

3a: chitin

Figure 10: Structures of polymer matrixes and soluble additives [77].
The crystal growth resulted in the formation of $\mathrm{CaCO}_{3}$ thin-film crystals of about $0.8 \mu \mathrm{m}$ in thickness. The crystallite size as measured by X-ray was $\sim 30 \mathrm{~nm}$. No precipitation was observed for the crystallization on the insoluble polymer matrices derivatives possessing no proton-donating group (cellulose and chitin), even in the presence of PAA, but rhombohedral calcite crystals were obtained in the absence of the acidic polymer PAA. Thin films grown on chitosan consisted of mainly vaterite and those of cellulose and chitin consist of only calcite in the absence of PAA, while those grown on chitosan mainly consist of vaterite in the presence of the PAA. Polymorphs formed on the thin films developed on chitin and cellulose was independent of the concentration of PAA, where as those of chitosan were dependent. A 
higher molecular weight of PAA led to less stable polymorphs.

The morphology and the crystal structure of films of calcium carbonate formed on chitosan (annealed at 100 and $260{ }^{\circ} \mathrm{C}$ ) in the presence of PAA with different molecular weights at various temperatures was investigated by Kotachi et al., [80] (Figure11). Granular particles were occasionally observed within the films. Irrespective of the crystal structure obtained the planar and circular appearances of the films were basically the same under all the conditions.

The diameter (Figure12) of circular chitosan films annealed at $260{ }^{\circ} \mathrm{C}$ was relatively larger than those of
$100{ }^{\circ} \mathrm{C}$ baked chitosan. XRD patterns of the films deposited on $260{ }^{\circ} \mathrm{C}$-baked chitosan in the presence of PAA (Mws $=2,000$ and 250,000) at various temperatures showed the dominance of calcite peaks at lower temperature $\left(10^{\circ} \mathrm{C}\right)$ while aragonite dominated at higher temperature $\left(35^{\circ} \mathrm{C}\right)$. Weak X-rays diffraction signals for vaterite were also observed with more found on PAA, $\left(\mathrm{Mw}=250,000,10^{\circ} \mathrm{C}\right.$ and $\left.35^{\circ} \mathrm{C}\right)$ and non on PAA, $\mathrm{Mw}=2,000,10^{\circ} \mathrm{C}$. Selective production of the various polymorphs was achieved by the variation of the molecular weight of PAA, and the temperature of the solution
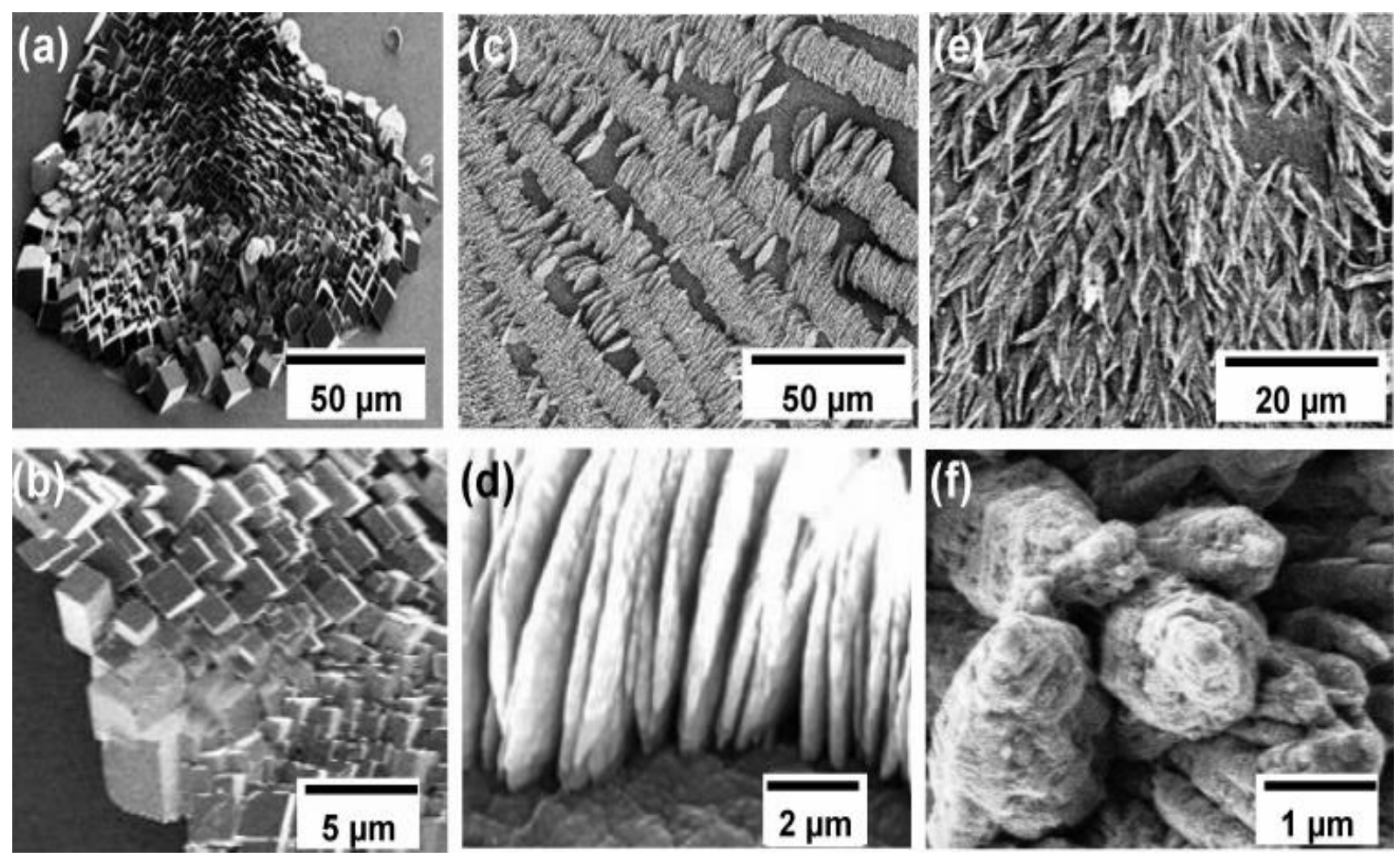

Figure11 SEM images of the development of the planar films into microarrays by the subsequent overgrowth without any additives for visual determination of the polymorphs: $(a, b)$ calcite; $(c, d)$ vaterite; $(e, f)$ aragonite [80].
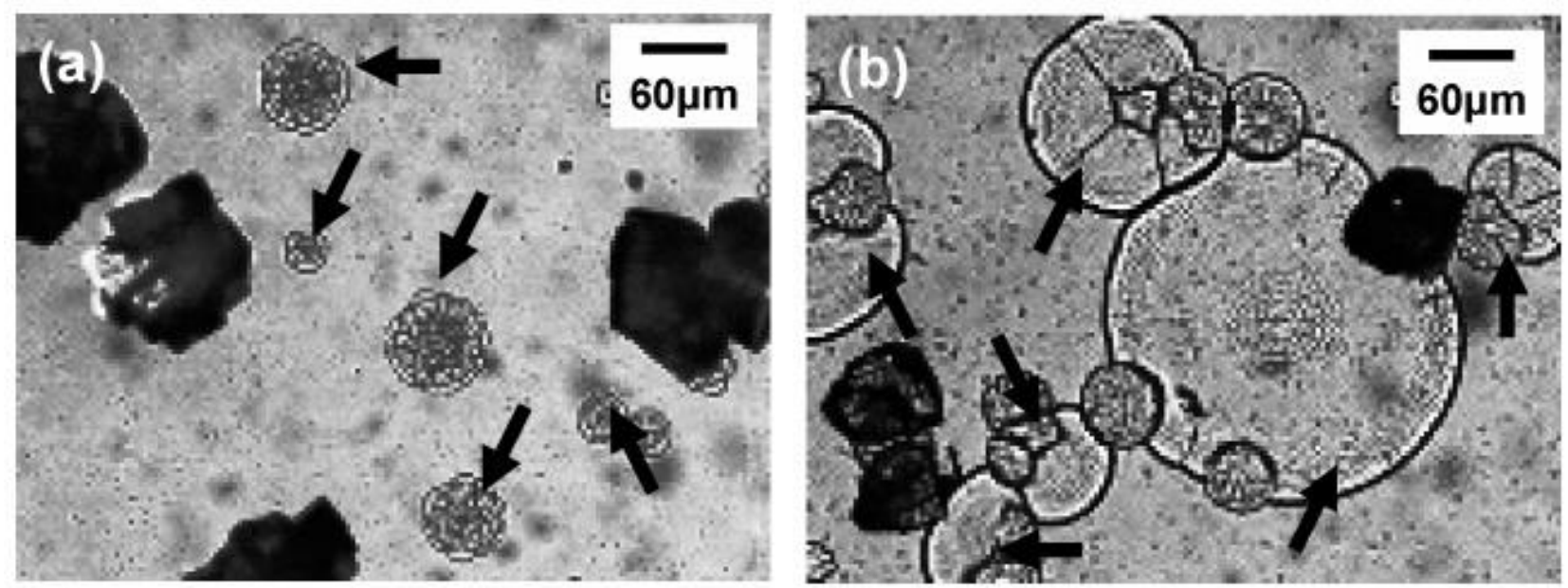

Figure 12 - Optical micrographs of calcium carbonate grown at $10{ }^{\circ} \mathrm{C}$ with $2.4 \times 10^{-3} \mathrm{wt} \%$ PAA250k on $100{ }^{\circ} \mathrm{C}$ (a) and $260{ }^{\circ} \mathrm{C}$ baked (b) chitosan. Arrows indicate planar films. Black shadows are granular particles [80]. 
Yamamoto et al., [78] used 5 wt \% of CHW prepared by acid hydrolysis to prepare $\mathrm{CaCO}_{3} /$ chitin-whisker hybrids, when the suspension was converted to a gel by exposing it to ammonium carbonate vapour. The chitin gel was used as a template and $\mathrm{CaCO}_{3}$ crystals were allowed to form for 30 days. Formation of spherical $\mathrm{CaCO}_{3}$ crystals started after 3 days without the existence of amorphous $\mathrm{CaCO}_{3}$. The crystals gradually increased in size until the gel matrix was filled with $\mathrm{CaCO}_{3}$ crystals after 30 days. Scanning electron microscopy image of the hybrid showed the presence of $\mathrm{CaCO}_{3}$ crystals in the gel matrix while Raman spectra, FTIR and XRD revealed calcite crystals.

\section{CONCLUSIONS}

Chitin is one of the biomaterials that is abundant and cheap. The availability of this material made the research interesting both to the industry and researchers. Been cheap and abundant, researchers are able to generate products and materials add value to humanity. Chitin especially in the whiskers form can add value to humanity when properly process. This article was aimed at reviewing the sources of chitin, its extraction, and the mechanical and thermal properties of $\mathrm{CHW}$ reinforced composites were also reviewed. The effect of $\mathrm{CaCO}_{3}$ growth on CHW/Polymer composites was also investigated. Depending on the source, three polymorphic forms of chitin are; namely $\alpha, \beta$ and $\gamma$ chitinsare found in nature. The most common and extensively investigated is $\alpha$-chitin because is stable and widely found in living organisms. The tensile properties of composites are improved by the addition of CHW. A clear trend of decrease in strain at break as CHW increases was established. Authors agreed that the increase in Young's modulus and tensile strength up to a certain percentage CHW loading is an indication of strong interactions between whiskers and the matrix. Above this percentage CHW loading the tensile strength either decreases or there is no significant increase. The same trend was observed for the Young's modulus, while the strain continues to decrease as CHW increases.

\section{REFERENCES}

[1] Aldousiri B, Dhakal HN, Onuh S Zhang ZY, Bennett N and Richardson MOW. Effect of layered silicate reinforcement on the structure and mechanical properties of spent polyamide-12 nanocomposites. Composites Part B: Engineering, 43:1363-1367. (2012).

[2] Ha S, Rhee K, Park SJ and Lee JH. Temperature effects on the fracture behaviour and tensile properties of silanetreated clay/epoxy nanocomposites. Composites Part B: Engineering, 41:602-607. (2010).
[3] Toro P, Quijada R, Arias I and Yazdani-Pedram M. Mechanical and Morphological Studies of Poly (propylene)-Filled Eggshell Composites. Macromolecular Materials and Engineering ;292:1027-1034. (2007).

[4] Masoodi R, El-Hajjar RF, Pillai KM and Sabo R. Mechanical characterization of cellulose nanofiber and bio-based epoxy composite. Materials and Design;36:570-576. (2012).

[6] Campanella A, La Scala J and Wool R. Fatty Acid-Based Comonomers as Styrene Replacements in Soybean and Castor Oil-Based Thermosetting. Journal of Applied Polymer Science;119:1000-1010. (2011).

[7] Erman E, Stanzione J, Reno K, Wool R and Miller M. Pyrolyzed Chicken Feather Fibers for Biobased Composite Reinforcement. Journal of Applied Polymer Science;128:983-989. (2013).

[8] Muzzarelli RAA., Ed. Chitin nanofibrils. In: Chitin and Chitosan, Opportunities and Challenges, New Age International, New Delhi, India (2005).

[9] Khor E and Lim LY. Implantable applications of chitin and chitosan. Biomaterials ;24: 2339-2349. (2003)

[10] Li J, Revol J. F. Marchessault RH. Effect of degree of deacetylation of chitin on the properties of chitin crystallites. Journal of Applied Polymer Science; 65:373380. (1997).

[11] Das S and Ganesh EA. Extraction of Chitin from Trash Crabs (Podophthalmus vigil) by an Eccentric Method. Journal of Biological Sciences;2: 72-75. (2010).

[12] Morin A and Dufresne A. Nanocomposites of chitin whiskers from Riftia tubes and poly (caprolactone). Macromolecules; 35:2190-2199. (2002).

[13] Aranaz I, Mengibar M, Harris R, Panos I, Miralles B, Acosta N, Galed G and Heras A. Functional characteristics of Chitin and Chiosan. Current Chemical Biology, 3:203230. (2009).

[14] Wongpanit P, Sanchavanakit N, Pavasant P, Bunaprasert T, Tabata $Y$ and Rujiravanit R. Preparation and characterization of chitin whisker-reinforced silk fibroin nanocomposite sponges. European Polymer Journal; 43: 4123-4135. (2007).

[15] Xu W, Mulhern PJ, Blackford BL, Jericho $\mathrm{MH}$ and Templeton I. A new atomic force microscopy technique for the measurement of the elastic properties of biological materials. Scanning Microscopy; 8 :499-506. (1994).

[16] Lu Y, Weng L and Zhang L. Morphology and properties of soy protein isolate thermoplastics reinforced with chitin whiskers. Biomacromolecules, 5: 1046-1051. (2004).

[17] Wu X, Torres F. G., Vilaseca F and Peijs TJ. Influence of the Processing Conditions on the Mechanical Properties of Chitin Whisker Reinforced Poly (caprolactone) Nanocomposites. Journal of Biobased Materials BioEnergy, 1:341-350. (2007).

[18] Feng L, Zhou Z, Dufresne A, Huang J, Wei M and An L. Structure and Properties of New Thermo foaming Bionanocomposites Based on Chitin Whisker-GraftPolycaprolactone. Journal of Applied Polymer Science (2009); 112:2830-2837.

[19] Rhazi M, Desbrieres J, Tolaimate A, Alagui A and Vottero P. Investigation of different natural sources of chitin: 
influence of the source and deacetylation process on the physicochemical characteristics of chitosan. Polymer International; 49:337-344. (2000).

[20] Ifuku S, Nogi M, Yoshioka M, Morimoto M, Yano $\mathrm{H}$ and Saimoto H. Fibrillation of dried chitin into 10-20 nm nanofibers by a simple grinding method under acidic conditions. Carbohydrate Polymers 81:134-139. (2010;)

[21] Minke R and Blackwell J. The structure of $\alpha$-chitin. Journal of Molecular Biology; 120:167-181. (1978).

[22] Mathur N. K, and Narang C. K. Chitin and Chitosan, Versatile Polysaccharides from Marine Animals. Journal of Chemical Education: 67:938-942 (1990).

[23] Cárdenas G, Cabrera G, Taboada E, Miranda SP. Chitin characterization by SEM, FTIR, XRD, and 13Ccross polarization/mass angle spinning NMR. Journal of Applied Polymer Science (2004); 93:1876-1885.

[24] Waldeck J, Daum G, Bisping B, and Meinhardt F. Isolation and molecular characterization of chitinase-deficient Bacillus licheniformisstrains capable of deproteinization of shrimp shell waste to obtain highly viscous chitin. Applied and Environmental Microbiology, 72:7879-7885. (2006).

[25] Kaur S and Dhillon GS. Recent trends in biological extraction of chitin from marine shell wastes: a review. Critical Reviews in Biotechnology, 1:1-18. (2013).

[26] Kaur S, Dhillon GS. The versatile biopolymer chitosan: potential sources, evaluation of extraction methods and applications. Critical Reviews in Microbiology,; 40: 155175. (2014).

[27] Poulicek, M and C. Jeuniaux. Chitin biodegradation in marine environments: An experimental approach. Biochemical Systematic and Ecology, 19:385-394. (1991).

[28] Cauchie HM. Chitin production by arthropods in the hydrosphere. Hydrobiologia 470: 63-96. (2002);

[29] Tröger C and Niranjan K. Sustainable Chitin extraction and Chitosan modification for application in the food industry. International conference on Food innovation, (2010).

[30] Synowiecki J, Al-Khateeb NA. The recovery of protein hydrolysate during enzymatic isolation of chitin from shrimp Crangoncrangon processing discards. Food Chemistry 68:147-152. (2000).

[31] Watthanaphanit A, Supaphol P, Tamura H, Takura S and Rujiravanit R. Fabrication, structure and properties of Chitin Whiskers-Reinforced Alginate Nanocomposite Fibers. Journal of Applied Polymer Science; 110:890-899. (2008).

[32] Al Sagheer F. A, Al-Sughayer, Muslim S and Elsabe MZ. Extraction and characterisation of chitin and chitosan from marine sources in Arabia Gulf. Carbohydrate Polymers,77:410-419. (2009).

[33] Dhillon G. S., Kaur S, Brar SK, VermaM.Green synthesis approach: extraction of chitosan from fungus mycelia. Critical Reviews in Biotechnology; 33:379-403,(2013).

[34] Percot A, Viton C, Domard A. (2003). Characterization of shrimp shell deproteinization. Biomacromolecules, 4:1380-1385. (2003).

[35] Khanafari A, Marandi, R and Sanatei S. Recovery of chitin and chitosan from shrimp waste by chemical and microbial methods. Iranian Journal of Environmental Health Science and Engineering, 5(1):19-24

[36] Jung WJ, Jo GH, Kuk JH, Kim KY, Park RD. Extraction of chitin from red crab shell waste by cofermentation with Lactobacillus parasei subsp. Tolerans KCTC-3074 and Serratiamacrescens FS-3. Applied Microbial and Physiology; 71:234-237. (2006).

[37] Zeng J, He Y, Li S and Wang Y. Chitin Whiskers: An Overview. Biomacromolecules, 13:1-11. (2012).

[38] Domard AI and Rinadudo M. Preparation and characterization of fully deacetylated chitosan. Journal of Biological Macromolecules; 5: 49-52. (1983).

[39] Mima S, Miya M, Iwamoto R and Yoshikawa S. Highly DeacetylatedChitosan and Its Properties. Journal of Applied Polymer Science; 28: 1909-1917. (1983).

[40] Pelletier A, Lemire I, Sygusch J, Chornet E and Overend RP. Chitin/chitosan transformation by thermo-mechanochemical treatment including characterization by enzymatic depolymerisation. Biotechnology and Bioengineering 36:310-315. (1990);

[41] Majeti NV and Kumar R. A Review of chitin and chitosan applications. Reactive and Functional Polymers; 46:1-27 (2000).

[42] Favier V, Chanzy $\mathrm{H}$ and Cavaille JY. Polymer Nanocomposites Reinfored cellulose whiskers. Macromolecules 28-6365-6367. (1995);

[43] Dufresne A, Kelerhals MB and Witholt B. Transcrystallization in Mcl-PHAs/Cellulose Whiskers Composites. Macromolecules, 32:7396-7401. (1999).

[44] Marchessault RH, Morehead RR and Walter NM. Liquid Crystal Systems from Fibrillar Polysaccharides. Nature. ; 184:632-633. (1959).

[45] Revol JF and Marchessault RH. In vitro chiral nematic ordering of chitin crystallites. International Journal of Biology Macromolecules; 15:329-335 (1993).

[46] Chang PR, Jian RJ, Yu JG and Ma XF. Starch-based composites reinforced with novel chitin nanoparticles. Carbohydrate Polymer, 80:420-425. (2010).

[47] Hariraksapitak, P and Supaphol, P. Preparation and Properties of $\alpha$-Chitin-Whisker-Reinforced HyaluronanGelatin Nanocomposite Scaffolds. Journal Of Applied Polymer Science 117: 3406-3418. (2010);

[48] Nair KG and Dufresne A. Crab shell chitin whisker reinforced natural rubber nanocomposites. 1. Processing and swelling behaviour. Biomacromolecules A; 4:657665. (2003).

[49] Nair KG and Dufresne A. Crab shell chitin whisker reinforced natural rubber nanocomposites. 2. Mechanical behaviour. Biomacromolecules B;4: 666-674. (2003).

[50] Sriupayo J, Supaphol P, Blackwell J and Rujiravanit R. Preparation and characterization of $\alpha$-chitin whiskerreinforced chitosan nanocomposite films with or without heat treatment. Carbohydrate Polymer A; 62: 130-136. (2005).

[51] Sriupayo J, Supaphol P, Blackwell J and Rujiravanit R. Preparation and characterization of $\alpha$-chitin whiskerreinforced poly(vinyl alcohol) nanocomposite films with or without heat treatment. Polymer B; 46: 5637-5644, (2005). 
[52] Goodrich JD and Winter WT. $\alpha$-Chitin Nanocrystals Prepared from shrimp shells and their specific surface area measurement. Biomacromolecules; 8:252-257. (2007).

[53] Junkasem J, Rujiravanit R, Grady BP and Supaphol P. X-ray diffraction and dynamic mechanical analyses of $\alpha$-chitin whisker-reinforced poly(vinyl alcohol) nanocomposite nanofibers. Polymer International; 59:85-91. (2010).

[54] Junkasem J, Rujiravanit R and Supaphol P. Fabrication of $\alpha$ chitin whisker-reinforced poly (vinyl alcohol) nanocomposite nanofibers by electrospinning. Nanotechnology 17:4519-4528. (2006);

[55] Phongying S, Aiba S and Chirachanchai S. Direct chitosan nanoscaffold formation via chitin whiskers. Polymer 48:393-400. (2007)

[56] Paillet $M$ and Dufresne A. Chitin whisker reinforced thermoplastic nanocomposites. Macromolecules, 34: 6527-6530, (2001).

[57] Ifuku S, Nogi M, Nogi M, Abe K, Yoshioka M, Morimoto M, Saimoto $\mathrm{H}$ and Yano H. Simple preparation method of chitin nanofibers with a uniform width of $10-20 \mathrm{~nm}$ from prawn shell under neutral conditions. Carbohydrate Polymer, 84:762-764. (2011).

[58] Habibi Y, Lucia LA, and Rojas OJ. Cellulose nanocrystals: chemistry, self-assembly, and application. Chemical Review, 110: 3479-3500. (2010).

[59] Saito Y, Putaux JL, Okano T, Gaill F and Chanzy H. Structural aspects of the swelling of $\beta$-chitin in $\mathrm{HCl}$ and its conversion into $\alpha$-chitin. Macromolecules; 30:3867-3873. (1997).

[60] Clark GL and Smith AF. X-ray diffraction studies of chitin, chitosan and derivatives. Journal of Physical Chemistry; 40:863-879. (1936)

[61] Fan YM, Saito T and Isogai A. Chitin nanocrystals prepared by Tempo-Mediated oxidation of $\alpha$-chitin. Biomacromolecules 9:192-198. (2008);

[62] Montanari S, Rountani M, HeuxL and Vignon MR. Topochemistry of carboxylated cellulose nanocrystals resulting from tempo-mediated oxidation. Macromolecules, 38:1665-1671, (2005).

[63] Inaba H, Hoshizawa M, Fujiwara A, Matsumura Y and Mori T. Textural Properties Of Starch Gels Filled With Collegen and Chitin. Journal of Texture Studies; 26:577-586. (1995).

[64] Peesan M, Rujiravanit R, and Supaphol P. Characteristics of beta-chitin/poly (vinyl alcohol) blend films. Polymer Testing; 22:381-387. (2003).

[65] He C and Ma B. The spinning, Structure, and properties of Cellulose/Chitin blend filaments through HWM method. Polymer Advanced Technology; 21:496-505. (2010).

[66] Zhang L, Guo J and Du Y. Morhpology and properties of cellulose/chitin blends membranes from $\mathrm{NaOH} / \mathrm{Thiourea}$ aqueous solution. Journal of Applied Polymer Science 86:2025-2032. (2002).
[67] Yusof NL, Lim LY and Khor E. Flexible chitin films: structural studies. Carbohydrate Research; 339:27012711. (2004)

[68] Azevedo MC and Reis RL. Development and properties of polycarprolactone / hydroxyapatite composite biomaterials. Journal of Materials Science: Materials in Medicine; 14:103-107. (2003)

[69] Faturechi R, Karimi A, Hashemi A, Yousefi H, Navidbakhsh M. Influence of poly(acrylic acid) on the mechanicalproperties of composite hydrogels. Advances in Polymer Technology;33:21487-21493. (2014).

[70] Faghihi S, Karimi A, Jamadi M, Imani R and Salarian R. Graphene oxide / poly (acrylic acid) / gelatin nanocomposite hydrogel: Experimental and numerical validation of hyperelastic model. Material Science and Engineering: C 38:299-305. (2004);

[71] Smitha B, Sridhar S and Akhan AA. Polyelectrolyte Complexes of Chitosan and Poly(acrylic acid) As Proton Exchange Membranes for Fuel Cells. Macromolecules; 37:2233-2239. (2004).

[72] Austin PR, Chitin solvents and solubility parameters, in Chitin and Chitosan and Related Enzymes, ed. by Zikakis JP. Academic Press, Orlando, FL, pp. 227-237 (1984).

[73] Rinaudo M. Chitin and chitosan: Properties and applications. Progress in Polymer Science 2006; 31: 603632

[74] No, HK and Meyers SP. Preparation and Characterization of Chitin and Chitosan: A Review. Journal of Aquatic Food Product Technology, 4(2):27-52. (1995).

[75] Sannan T, Kurita K and Iwakura Y. Studies on Chitin,2. Effect of Deacetylation on Solubility. Macromolecular Chemistry and Physics, 177: 3589-3600. (1976).

[76] Kubota N and Eguchi Y.Facile preparation of water-soluble $\mathrm{N}$-acetylated chitosan and molecular weight dependence of its water-solubility. Polymer Journal; 29:123-127. (1997).

[77] Suzuki M, Saruwatari K, Kogure T, Yamamoto Y, Nishimura T, Kato T and Nagasawa H. An Acidic matrix protein, Pif, is a key macromolecule for Nacre formation. Science 325:1388-1390. (2009);

[78] Hosoda N and Kato T. Thin-Film Formation of Calcium Carbonate Crystals: Effects of Functional Groups of Matrix Polymers. Chemistry of Materials; 13: 688-693. (2001).

[79] Yamamoto $\mathrm{Y}$, Nishimura $\mathrm{T}$, Saito $\mathrm{T}$ and Kato

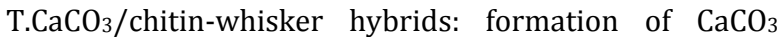
crystals in chitin-based liquid-crystalline suspension. Polymer Journal, 42:583-596. (2010).

[80] Nishimura T, Ito T, Yamamoto Y, Yoshio M. and Kato, T. Macroscopically ordered polymer/CaCO3 hybrids prepared by using a liquid-crystalline template. Angewandte International Edition; 47:2800-2803. (2008).

[81] KotachiA, Miura T and Imai H. Polymorph Control of Calcium Carbonate Films in a Poly (acrylicacid)/Chitosan System. Crystal Growth and Design, 6:1635-1641 (2006). 